\title{
EL NACIONALISMO VASCO EN EL TIEMPO DE LAS IRMANDADES DA FALA: MODERADOS, RADICALES Y HETERODOXOS (1916-1923)*
}

José Luis de la Granja Sainz

Universidad del País Vasco/

Euskal Herriko Unibertsitatea (UPV/EHU)

DOI: $10.17075 /$ iftpc.2021.009

* Este estudio se ha realizado en el marco del proyecto de investigación PGC2018-094133-B-100 (MCIU/AEI/FEDER, UE), dentro de un grupo de investigación de la Universidad del País Vasco (GIU 20/02). 



\section{INTRODUCCIÓN}

Los años de surgimiento del nacionalismo gallego con las primeras Irmandades da Fala entre 1916 y 1923 son también importantes en la trayectoria del nacionalismo vasco, pues constituyen una etapa relevante dentro del período histórico que transcurre desde la muerte de Sabino Arana (1865-1903), su fundador, en noviembre de 1903, hasta el golpe de Estado del general Miguel Primo de Rivera, que instaura su dictadura en septiembre de 1923. Si esta última fecha marca claramente su límite final, el inicio de esta etapa podría adelantarse a 1914, el año del estallido de la I Guerra Mundial. Pese a la neutralidad española en ella, la Gran Guerra tuvo mucha repercusión en la monarquía de la Restauración, que sufrió la triple crisis de 1917: militar (las Juntas de Defensa), política (la Asamblea de Parlamentarios en Barcelona) y social (la huelga general revolucionaria del movimiento obrero). También incidió mucho en el País Vasco, cuya economía vivió unos años de vacas gordas, sobre todo la Naviera Sota-Aznar, que se enriqueció con el comercio internacional, en especial con Gran Bretaña, hasta el punto de que la Corona británica ennobleció con el título de Sir al gran naviero Ramón de la Sota Llano (1857-1936), quien había ingresado en el Partido Nacionalista Vasco (PNV) en 1898 y representaba su tendencia moderada.

Esta breve e intensa coyuntura de crecimiento económico fue acompañada del auge político del nacionalismo vasco, el mayor antes de la II República, como reflejan estos datos: consiguió una neta (aunque efímera) hegemonía política en Vizcaya, al ganar todas las elecciones en 1917-1918; dejó de ser el partido de los bizkaitarras: así eran llamados los nacionalistas por el título de su primer periódico (Bizkaitarra, 1893-1895) y por ser Vizcaya su cuna y su feudo, pues se expandió por los otros territorios vascos (sobre todo, Guipúzcoa); hubo 
por primera vez una minoría nacionalista vasca en las Cortes (1918) y se planteó la cuestión de la autonomía vasca, que fue un antecedente histórico de los Estatutos de 1936 y 1979.

De todos modos, empiezo a partir del año 1916 por producirse en él dos hechos significativos: la expulsión de Luis Arana (1862-1951), el hermano de Sabino, y el cambio de nombre del PNV por primera y única vez en su dilatada historia; ese año pasó a denominarse Comunión Nacionalista Vasca, nombre que mantuvo hasta noviembre de 1930, cuando los dos partidos aranistas, que se habían dividido en 1921, se reunificaron con el nombre de Partido Nacionalista Vasco.

Si las fuerzas españolas se dividieron en aliadófilas (las izquierdas) y germanófilas (las derechas) en relación con los dos bandos beligerantes en la I Guerra Mundial, el derechista PNV se posicionó a favor de los países aliados y democráticos (Gran Bretaña, Francia y Estados Unidos) por ser esta también la causa de las nacionalidades del centro y del sureste de Europa, sometidas por los imperios alemán, austrohúngaro y turco. Como excepción, Luis Arana, presidente del partido, fue germanófilo; pero no radicó aquí el motivo fundamental de su expulsión del PNV, como demostró Ludger Mees (1992). El cese de Luis Arana obedeció a varias razones: su talante autoritario y sin el carisma de su hermano; su «imperialismo bizkaitarra», que postergaba al nacionalismo no vizcaíno; su pésima gestión económica, que llevó al PNV al borde de la bancarrota, y, sobre todo, su pacto secreto con el gobernador civil de Vizcaya en las elecciones municipales de noviembre de 1915, por el cual daba la alcaldía de Bilbao a un concejal monárquico. Al conocerse dicho pacto, Luis Arana fue destituido de la presidencia del PNV y expulsado a principios de 1916. Con él abandonó el partido un grupo reducido de veteranos nacionalistas vizcaínos, que refundó el Euzkeldun Batzokija (nombre del primer centro nacionalista, creado por Sabino Arana en Bilbao en 1894, que fue el embrión del que nació al año siguiente el PNV) y publicó un nuevo periódico Bizkaitarra (1916-1919), opuesto a la estrategia autonomista preconizada por Ramón de la Sota Llano y los dos 
principales ideólogos de esta etapa: Luis Eleizalde (1878-1923) y Engracio Aranzadi (1873-1937), más conocido por su seudónimo Kizkitza.

Además, en diciembre de 1916 el PNV cambió oficialmente su nombre por el de Comunión Nacionalista Vasca, si bien ya lo venía utilizando desde la aparición de su diario oficial, Euzkadi, publicado en Bilbao de 1913 a 1937, cuyo primer director fue Kizkitza. A mi juicio, dicho cambio tenía un doble significado. Por un lado, el PNV no era un partido especializado (en la terminología de Maurice Duverger), sino que se trataba de un "partido-comunidad con vocación de totalidad», es decir, un partido-movimiento que congregaba en su derredor a una amplia comunidad nacionalista interclasista, encuadrada a través de numerosas organizaciones satélites de carácter social, cultural y deportivo: era «la patria vasca en marcha», según su líder José Antonio Aguirre en la II República (Granja 2002). Por otro lado, el nombre de «Comunión» (empleado también por el carlismo, del que procedían Sabino Arana y los primeros nacionalistas vascos) confirmaba que el catolicismo constituía un elemento esencial, común a todos sus integrantes: fieles que formaban una especie de "partido-Iglesia». Y el otro elemento fundamental que aglutinaba al conjunto de la comunidad nacionalista era el aranismo. Más que una ideología, el aranismo era una doctrina político-religiosa, incuestionable por la mitificación sacralizada hecha de la figura del padre fundador tras su prematura muerte, con solo 38 años, en 1903: «el culto a Sabino Arana», denominado así por la prensa nacionalista de la época, era una segunda religión, yuxtapuesta a la católica, para sus seguidores, tal y como analicé en el libro Ángel o demonio: Sabino Arana. El patriarca del nacionalismo vasco (Granja 2015).

A diferencia del catalanismo y del galleguismo, cuya división principal era derechas/izquierdas, la línea de fractura del nacionalismo vasco en la Restauración (y a lo largo de su historia) va a ser moderación versus radicalismo. Fracasado por completo el intento de Francisco Ulacia (1868-1936), exconcejal de Bilbao y escritor, de crear un partido nacionalista liberal y republicano en el Bilbao de 1910-1912, el movimiento nacionalista vasco fue sinónimo de aranismo y de 
catolicismo durante las tres primeras décadas del siglo XX, porque todos los abertzales (en sentido etimológico, patriotas vascos) eran aranistas y católicos. Esto lo situaba en la derecha del espectro político, por lo que solo se podía aliar con otras fuerzas católicas, como el carlismo, el integrismo, el Partido Conservador o la Lliga Regionalista de Cataluña.

Políticamente, el nacionalismo vasco era muy simple: se componía de un único partido, el PNV, que se hallaba dividido en dos tendencias, la radical y la moderada, desde que en 1898 el grupo fuerista de Ramón de la Sota Llano ingresó en el pequeño partido de Sabino Arana y pasó a ser su corriente moderada y autonomista. Tras la muerte del fundador, aranistas y sotistas se enfrentaron por controlar el partido. La rivalidad entre radicales y moderados persistió en la coyuntura de 1916-1923, en la que cambiaron sus denominaciones: estos últimos pasaron a llamarse comunionistas (por el nuevo nombre del partido), mientras que los radicales eran conocidos como los aberrianos, por el nombre de su órgano de prensa, el semanario bilbaíno Aberri (1916-1923). Si en los años de éxitos electorales estuvieron unidos, a partir del retroceso electoral aumentaron sus disputas hasta culminar en la ruptura de 1921 con la división en dos partidos muy enfrentados: la Comunión Nacionalista Vasca y el Partido Nacionalista Vasco o Aberri, al retomar los radicales el nombre tradicional y su sigla PNV.

Cabe plantear si no hubo entonces una tercera vía, esto es, un nacionalismo vasco que no fuese aranista ni católico confesional, sino democrático-liberal y dispuesto a aliarse con las izquierdas republicana y socialista. Orgánicamente no existió hasta la fundación de Acción Nacionalista Vasca (ANV) en Bilbao en 1930, en vísperas del advenimiento de la II República. Pero, ideológicamente, sí hubo unos pocos precursores durante la Restauración: el citado Francisco Ulacia, el primer nacionalista vasco de izquierda y anticlerical; Jesús Sarría (1887-1922) y Eduardo Landeta (1867-1957). A ellos los denominé «heterodoxos», por situarse fuera de la ortodoxia aranista imperante, y los consideré pioneros de una tercera vía del movimiento abertzale, «el nacionalismo vasco heterodoxo en el 
siglo $\mathrm{XX}$ : tal fue el título de un artículo que publiqué en gallego en la revista Grial (Granja 1998). En ella incluí también a ANV, al pequeño partido ESEI en la Transición y a la Euskadiko Ezkerra de los años 80 hasta su fusión con el Partido Socialista de Euskadi en 1993, cuando desapareció esta corriente. El nacionalismo heterodoxo ha sido muy débil en comparación con las dos grandes tendencias en que se ha dividido este movimiento hasta nuestros días: la moderada, encarnada casi siempre por el PNV, y la radical, representada por Aberri en los años veinte, el grupo Jagi-Jagi en los treinta y desde 1959 por ETA y las numerosas organizaciones surgidas o escindidas de esta y de su brazo político Herri Batasuna (1978), cuyos herederos ideológicos son Sortu y Euskal Herria Bildu en la actualidad.

Aplicando este esquema tripartito a la etapa de 1916-1923, voy a tratar sucesivamente de los moderados, los radicales y los heterodoxos: primero, la estrategia autonomista de la Comunión hasta su fracaso en 1919; después, la rebelión y escisión de Aberri hasta su integración en la Triple Alianza de 1923, y, por último, el pensamiento de Sarría y Landeta, que pretendía la renovación ideológica del nacionalismo vasco en la primera posguerra mundial.

\section{LA ESTRATEGIA AUTONOMISTA DE LA COMUNIÓN NACIONA- LISTA VASCA}

Tras la defenestración de Luis Arana, la Comunión se aprestó a seguir la vía posibilista trazada por sus ideólogos Kizkitza y Eleizalde desde las páginas del diario Euzkadi. Discípulos de Sabino Arana, ambos evolucionaron desde su radicalismo juvenil hasta planteamientos políticos moderados, pero siempre dentro de la ortodoxia aranista, nunca cuestionada, según refleja el libro de Kizkitza La nación vasca (1918 y 1931), la mejor síntesis doctrinal del nacionalismo vasco en el primer tercio del siglo Xx. Ellos se encargaron de legitimar la política autonomista, afirmando que la independencia era un medio y no un fin, que 
nacionalismo no era sinónimo de separatismo y que la supervivencia de la nación vasca era más importante que su independencia. Asimismo, sostuvieron que el nacionalismo debía anteponer la acción social y cultural (la recuperación del «alma nacional vasca») a la acción política. Sin embargo, el nacionalismo vasco fue ante todo un movimiento político, bajo la hegemonía del partido guía, al cual se subordinaron tanto el movimiento cultural, vehículo de expresión de la doctrina aranista, como el sindical: Solidaridad de Obreros Vascos (SOV), entonces un pequeño sindicato, creado por el PNV en Bilbao en 1911 para agrupar a los obreros católicos frente al predominio socialista de la Unión General de Trabajadores (UGT).

Los años dorados de la Comunión Nacionalista fueron 1917-1919, cuando sus triunfos en las urnas le proporcionaron una efímera hegemonía política en Vizcaya, interrumpiendo la ostentada por el monarquismo conservador durante casi toda la Restauración. En esos años la Comunión marchó a remolque de la Lliga Regionalista, que había conseguido la Mancomunidad catalana en 1914 y reclamaba la «autonomía integral» en el reinado de Alfonso XIII. Su manifiesto-programa Per Catalunya i l'Espanya Gran, redactado en 1916 por Enric Prat de la Riba, presidente de la Mancomunidad, fue expuesto por su líder Francesc Cambó en importantes discursos pronunciados en Bilbao y San Sebastián en 1917 y en sus viajes a Galicia y otras regiones. Por eso, la Comunión relegó su reivindicación inicial de una Mancomunidad vasca y pasó a demandar un estatuto de autonomía para Euskadi.

Entonces se dio una entente cordial de los nacionalismos moderados catalán y vasco, personificados por sus dirigentes Cambó y De la Sota, quienes actuaron conjuntamente y lograron que fracasase el proyecto de ley del ministro de Hacienda, el liberal Santiago Alba, para gravar con un impuesto especial los beneficios extraordinarios obtenidos por las empresas con ocasión de la I Guerra Mundial. La diferencia entre aquellos estriba en que Cambó fue sobre todo un destacado político de la Lliga, que fue diputado muchos años y ministro en dos Gobiernos de concentración de Antonio Maura (1918 y 1921-1922), si bien 
llegó a ser también un rico hombre de negocios a nivel internacional (presidente de la multinacional CHADE), mientras que De la Sota fue principalmente un gran empresario con múltiples negocios (astilleros, navieras, bancos y minas), que solo pisó las Cortes para jurar su cargo de diputado por Valmaseda en 1918, el único que tuvo con el PNV.

La prueba evidente del auge del nacionalismo vasco fueron sus sucesivos éxitos en las elecciones. En las provinciales de marzo de 1917 logró su primera mayoría en la Diputación de Vizcaya, que fue presidida por Ramón de la Sota Aburto (1887-1978), el hijo mayor del naviero. Después, en las municipales de noviembre del mismo año, obtuvo la alcaldía de Bilbao, numerosos concejales en Vizcaya, bastantes en Guipúzcoa y varios en San Sebastián y Pamplona. Y en las legislativas de febrero y marzo de 1918 sacó siete diputados (cinco por Vizcaya, uno por Guipúzcoa y uno por Navarra) y los tres senadores vizcaínos: uno de ellos fue el destacado escritor navarro Arturo Campión (1854-1937). Por vez primera en la historia, el nacionalismo vasco contaba con un grupo parlamentario; la mayoría de sus miembros estaban vinculados a Ramón de la Sota Llano. La Comunión había conseguido hacerse con casi todo el poder político en Vizcaya; tan solo le faltaba el distrito de Bilbao, el feudo de las izquierdas, que había pasado del capitalista republicano Horacio Echevarrieta al líder socialista Indalecio Prieto, convertido en la «bestia negra» del nacionalismo vasco, hasta el punto de que su periódico oficial llegó a afirmar: «El españolismo es, en Euzkadi, Indalecio Prieto Tuero» (Euzkadi, 18-V-1919).

El ascenso nacionalista contribuyó a que la cuestión vasca se debatiese en las Cortes de 1918, donde los diputados comunionistas recibieron tanto las críticas de Prieto, por su clericalismo, como los duros ataques del carlista Víctor Pradera, por considerarlos separatistas. Ya en 1917 las tres diputaciones vascas, por iniciativa de la vizcaína, enviaron un mensaje al Gobierno del liberal Manuel García Prieto solicitando la reintegración foral o, en caso de ser rechazada, una amplia autonomía «dentro de la unidad de la nación española». Este reconocimiento, insólito en el nacionalismo vasco, era una prueba flagrante de 
la moderación política adoptada por la Comunión en su campaña autonomista de 1917-1919, como manera de atraer a otras fuerzas vascas. Empero, eso no fue óbice para que al mismo tiempo su dirección tratase de lograr eco internacional a sus reivindicaciones con el telegrama de sus diez parlamentarios al presidente norteamericano Woodrow Wilson, fechado el 25 de octubre de 1918, por ser el aniversario de la ley de 1839, que confirmó los Fueros vascos dentro de «la unidad constitucional de la monarquía» española (ley que consideraban el final de «la independencia del pueblo vasco», según la invención de la historia de Sabino Arana): pretendían que el autor de los famosos «Catorce Puntos» (1918) tuviese en cuenta a Euskadi «al establecerse las bases de la futura paz mundial». Pese a algunas gestiones de la Comunión, el caso vasco no se planteó en la Conferencia de Paz de París, tras la I Guerra Mundial, ni tampoco en la naciente Sociedad de Naciones.

La campaña autonomista no tuvo éxito en las Cortes. Una comisión extraparlamentaria, nombrada por el Gobierno liberal del conde de Romanones, elaboró un tímido anteproyecto de Estatuto vasco, que suponía una mera descentralización administrativa, mientras que una subponencia de tres diputados vascos (el nacionalista Pedro Chalbaud, el integrista Manuel Senante y el liberal José Orueta) redactó un proyecto de amplia autonomía política en 1919. Pero ninguno de ellos prosperó (como tampoco en el caso catalán) debido a la vuelta del líder conservador Antonio Maura -contrario a las autonomías- a la presidencia del Gobierno, así como a causa de la disolución de esas Cortes, que tuvieron poco más de un año de vida.

El año 1919 marcó el punto de inflexión en la trayectoria, hasta entonces ascendente, de la Comunión, pues fue el inicio de su retroceso electoral (se quedó con solo dos diputados al ser anuladas tres actas), que quitó importancia al problema vasco e hizo inviable la solución autonómica. En ello influyó la formación ese mismo año de la Liga de Acción Monárquica, la coalición de los liberales de Gregorio Balparda, los conservadores de Luis Salazar y los mauristas de Ramón Bergé en Vizcaya, unidos contra el nacionalismo, al cual derrotaron 
contando con la ayuda de un acuerdo de no enfrentamiento con el PSOE de Prieto, quien salió cuatro veces diputado por Bilbao, entre 1918 y 1923, venciendo siempre a los candidatos nacionalistas. En los comicios legislativos de 1920 y 1923, la confrontación entre la Comunión y la Liga se saldó con el triunfo absoluto de esta última en los cinco distritos restantes de Vizcaya (Baracaldo, Valmaseda, Guernica, Durango y Marquina), recuperando así los monárquicos la hegemonía política que habían ostentado hasta 1917. Desde 1920 la Comunión, que perdió también el escaño de Vergara, se quedó con un único diputado: Manuel Aranzadi (1882-1942), por Pamplona, elegido no por la fortaleza del nacionalismo en Navarra, sino por su alianza con el carlismo y otros sectores derechistas. Además, en 1919 perdió la mayoría en la Diputación de Vizcaya, que volvió a estar controlada por los monárquicos, y al año siguiente la alcaldía de Bilbao, que pasó al socialista Rufino Laiseca, amigo de Prieto.

\section{LA REBELIÓN DE LAS JUVENTUDES RADICALES Y LA ESCISIÓN DE ABERRI}

Al fracaso de la campaña autonomista y a los reveses electorales de la Comunión se sumó la lucha interna entre las dos tendencias habituales del nacionalismo vasco, que rebrotó a partir de 1919 y culminó en el cisma de 1921. Su origen estuvo en la discrepancia de la corriente radical con la estrategia política moderada llevada a cabo por los dirigentes y parlamentarios de la Comunión. Los radicales tenían mucha influencia en las organizaciones juveniles, denominadas Juventudes Vascas, numerosas en Vizcaya; su bastión era la dinámica Juventud Vasca de Bilbao, fundada en 1904; contaban con un líder carismático, Elías Gallastegui (Gudari, 1892-1974), y con un semanario militante, Aberri (convertido en diario en 1923), defensor a ultranza de la «pureza doctrinal» aranista, que consideraban desvirtuada por el «evolucionismo» de la Comunión. Por eso, estos jóvenes, que se declaraban separatistas y antiespañoles, disintieron de la posición 
contraria al independentismo, expresada tanto por el diputado Aranzadi en las Cortes como por Eleizalde y Kizkitza en el diario Euzkadi, posición que fue refrendada por la dirección de la Comunión en Navarra (NBB) y en toda Euskadi (EBB): «No somos separatistas».

En el verano de 1921, ante la rebeldía del ala radical, la Comunión expulsó a bastantes Juventudes Vascas y a varios de sus dirigentes, entre ellos Gallastegui y Manuel Eguileor. Los expulsados acordaron constituirse en partido y retomaron el nombre de Partido Nacionalista Vasco, partido que fue conocido también como Aberri por la cabecera de su periódico; de ahí que sus afiliados fuesen denominados aberrianos. A él se unió en 1922 el pequeño grupo de Luis Arana, quien fue nombrado su presidente, mientras que Gallastegui continuó presidiendo Juventud Vasca de Bilbao, el feudo del nuevo partido, al que se adhirieron veinte Juventudes Vascas, la gran mayoría vizcaínas (ocho siguieron con la Comunión). La escisión de Aberri tuvo mucha importancia en Bilbao, foco del independentismo, y en su hinterland industrial, donde venció a la Comunión en las elecciones municipales de 1922. En cambio, en la zona rural vizcaína y en las otras provincias vascas tuvo pocos seguidores y predominaron claramente los comunionistas.

Si el modelo de estos era el catalanismo moderado de la Lliga, partido burgués y conservador, el modelo de los aberrianos fue el nacionalismo radical irlandés del Sinn Féin desde la Pascua sangrienta de Dublín en 1916, a la que vieron con simpatía, al contrario del diario Euzkadi, que condenó su insurrección armada contra Gran Bretaña en plena I Guerra Mundial. A imitación de la organización femenina irlandesa Cumann na mBan (Liga de Mujeres), en 1922 Aberri creó Emakume Abertzale Batza (Asociación de la Mujer Patriota), presidida por Karmele Errazti, que tuvo escasa implantación entonces, pero fue muy numerosa en la República (Ugalde 1993). Además, potenció los grupos sectoriales, desarrollando el tipo de partido-comunidad, en especial los montañeros o mendigoizales, que se definían como «apóstoles del ideal sabiniano y soldados de la patria vasca» y serán la base de los batallones nacionalistas en la Guerra Civil. 
Su ideólogo Gallastegui y su periódico Aberri llevaron a cabo una intensa campaña de agitación y propaganda contra la guerra colonial de España en Marruecos y la participación en ella de jóvenes vascos, solidarizándose con los rifeños de Abd el-Krim: «iGuerra a la guerra!» fue su consigna (Gudari 1933). Para ello, recurrieron al teatro mediante la escenificación del relato fuerista y antibelicista Pedro Mari (1896), de Arturo Campión, que concluía con el fusilamiento del protagonista de ficción, el joven navarro Pedro Mari, convertido en «héroe inmortalizado de la Patria» por Gallastegui.

El manifiesto de Aberri, elaborado en 1922 por Luis Arana, era un mero resumen de las ideas básicas de su hermano Sabino, a quien los aberrianos adoraban, hasta el punto de que su mayor movilización de masas fue una peregrinación multitudinaria, en junio de ese año, para visitar la tumba del Maestro del nacionalismo vasco en el pequeño cementerio de Pedernales (hoy Sukarrieta), junto a la ría de Guernica. A mi juicio, constituyó un precedente del primer Aberri Eguna o Día de la Patria Vasca, celebrado en Bilbao el Domingo de Resurrección de 1932 y organizado por antiguos aberrianos en homenaje a Sabino y Luis Arana. Dicho manifiesto no aportaba ninguna novedad, ni tenía ninguna diferencia sustancial con la también aranista Comunión. No en vano ambos partidos asumían el lema sabiniano JEL ("Jaun-Goikua eta Lagi-Zarra», «Dios y Ley Vieja [o Fueros]»), del que procede el término jeltzale, con el que se denomina hasta hoy a los miembros del PNV. La única diferencia perceptible era su clara reivindicación de la independencia de Euskadi, que los moderados solían camuflar con la meta de la restauración plena de los Fueros, mediante la derogación de la ley de 1839, desde el manifiesto de 1906, que estuvo vigente hasta la Transición.

El programa de Aberri no abordaba los problemas sociales y económicos, notable carencia compartida con la Comunión. Esta se caracterizó por recurrir a la doctrina social de la Iglesia y por su neutralidad ante la cuestión social. Tal neutralidad resultaba conveniente en el seno de una comunidad nacionalista muy interclasista, que incluía desde el gran capitalista De la Sota hasta los obreros que 
trabajaban en su astillero Euskalduna de Bilbao y estaban afiliados al sindicato SOV. Es cierto que Gallastegui procuró dar a Aberri un tono anticapitalista (que también se observó en Sabino Arana hasta 1898), pero no cabe considerar a Aberri un partido de izquierda: su presidente fue el integrista Luis Arana y siempre constituyó un enemigo acérrimo del socialismo de Prieto. Esto llevó a Gallastegui a solidarizarse con los comunistas vizcaínos escindidos del PSOE y represaliados por la policía en 1923. Aun siendo Aberri un partido menos conservador que la Comunión, su fundación en 1921 no se debió a la fractura derechas/izquierdas, sino a la línea divisoria tradicional en el nacionalismo vasco entre moderación y radicalismo. Así lo confirma el hecho de que Juventud Vasca de Baracaldo, expulsada de la Comunión, se separase enseguida de Aberri para formar un efímero Partido Nacional Vasco (1922-1923), de carácter aconfesional y obrerista, que fue un antecedente de Acción Nacionalista Vasca, a la cual se incorporó la resurgida Juventud Vasca de Baracaldo en 1930-1931.

La política de alianzas distanció a los dos partidos aranistas, cuyas relaciones iniciales fueron malas y cuya división coadyuvó a sus derrotas electorales. Mientras que la Comunión admitía pactos con fuerzas vascas católicas y derechistas, como los carlistas, aunque no fuesen nacionalistas, Aberri solo aceptaba pactar con fuerzas nacionalistas, aunque no fuesen vascas. Por eso, en el verano de 1923 el partido de Gallastegui se sumó con entusiasmo a la propuesta del catalanismo (la Acció Catalana de Lluís Nicolau i d'Olwer y Antoni Rovira i Virgili, escindida de la Lliga en 1922, y el Estat Català de Francesc Macià, nacido también en 1922) de formar una alianza, autodenominada «internacional», de los tres nacionalismos periféricos, contando con el emergente galleguismo de las Irmandades da Fala y la Irmandade Nazonalista Galega de Vicente Risco. Esta Triple Alianza, dirigida contra España y a favor de la independencia de Cataluña, Euskadi y Galicia, fue sellada en Barcelona el 11 de septiembre de 1923, con motivo de la Diada de Cataluña.

El «Pacto de amistad y alianza entre los patriotas de Cataluña, Euskadi y Galicia» tenía forma de tratado internacional y se centraba en la denuncia del 
«régimen impuesto por el Estado español a Cataluña, Euskadi y Galicia» y en la reivindicación del «derecho de las tres naciones a disponer libremente de los propios destinos y a vivir según un régimen de plena soberanía política». Para ello, afirmaban su voluntad de «conquistar [...] la libertad nacional» mediante «el derecho a la apelación heroica» y, en caso necesario, «mezclar la sangre en el sacrificio», en alusión al recurso a la violencia para alcanzar la independencia.

Esto mostraba el influjo del nacionalismo irlandés (que en 1921 había conseguido separarse de Gran Bretaña con la creación del Estado Libre de Irlanda, sin el Ulster) sobre los nacionalistas radicales del Estado español. Pero su maximalismo independentista no iba acompañado de una mínima concreción de los medios necesarios para lograr sus fines, ni siquiera para establecer relaciones permanentes entre los tres movimientos: tan solo acordaban constituir un "Consejo de tres delegados, uno por cada nación», como representantes de las organizaciones firmantes del texto. Para los historiadores Anna Sallés y Enric Ucelay-Da Cal (1985), se trataba de un pacto grandilocuente, que lo anunciaba todo respecto a la autodeterminación, pero que no concretaba nada sobre cómo conseguirla.

Así quedó patente dos días después, el 13 de septiembre, cuando se produjo también en Barcelona el golpe de Estado del general Primo de Rivera, a quien le vinieron bien los disturbios habidos en las manifestaciones de los nacionalistas el día 11 para justificar su pronunciamiento, preparado de antemano, con un alcance mucho mayor que el de su componente antinacionalista. La dictadura militar, al perseguir enseguida, con el decreto antiseparatista del 18 de septiembre, a los nacionalismos radicales (no a los moderados de la Lliga y la Comunión), hacía realidad el supuesto del pacto sobre el «derecho a la apelación heroica», esto es, a la resistencia armada. Mas esta no llegó a producirse, pues el golpe de Primo de Rivera mató a la recién nacida Triple Alianza, que desapareció, a pesar de estar todavía en Barcelona sus firmantes, quienes optaron por esconderse, exiliarse o abandonar la actividad política. 
Por tanto, la Triple Alianza no pasó de ser «un pacto coyuntural y táctico, de carácter más testimonial que político» (Otaegui 1985), ya que no tuvo ninguna eficacia práctica. Prueba de ello fue que la lucha contra la Dictadura encabezada por Estat Català no contó con la ayuda de los galleguistas, ni de los nacionalistas vascos (salvo unos pocos aberrianos), por lo que Macià hubo de pactar con anarquistas y comunistas. Y nadie tuvo interés en resucitar la Triple Alianza tras la caída de la Dictadura en 1930. (La siguiente alianza entre los nacionalismos periféricos, la Galeuzca de la República o Pacto de Compostela de 1933, fue muy diferente, de índole autonomista y federal, pero también fracasó y su vida fue muy efímera, según estudié en el Congreso Castelao, cuyas actas fueron editadas por Justo Beramendi y Ramón Villares en 1989).

Por su parte, la Comunión Nacionalista envió a Barcelona representantes (uno de ellos fue Jesús María Leizaola, futuro lehendakari del Gobierno vasco en el exilio), pero no suscribió el pacto por no compartir su extremismo. La Lliga estuvo totalmente al margen de la Triple Alianza, que iba contra el proyecto regionalista de Cambó.

En Barcelona quedaron de manifiesto las diferencias políticas entre la Comunión y Aberri. Los dos eran partidos aranistas, que encarnaban las interpretaciones moderada y radical del legado del fundador del PNV. No diferían apenas en la doctrina ni en su concepción de la nación vasca, basada en la religión católica, la raza vasca, el euskera y la visión aranista de los Fueros. Su mayor divergencia estribaba en la táctica y la estrategia políticas para lograr la meta de la restauración foral o la independencia: si la vía autonómica era acertada (Comunión) o equivocada (Aberri); si se podía colaborar con España para aprobar un estatuto de autonomía (Comunión) o no por considerarla el «Estado opresor» de Euskadi (Aberri). Ni los comunionistas ni los aberrianos asumieron la controvertida «evolución españolista» (sinónimo de regionalista) de Sabino Arana al final de su vida (1902-1903), que suponía la renuncia a un Estado vasco independiente. 


\section{EL PENSAMIENTO NACIONALISTA HETERODOXO DE JESÚS SARRÍA Y EDUARDO LANDETA}

Sí estuvieron dispuestos a renunciar expressis verbis a la independencia de Euskadi los nacionalistas heterodoxos Jesús Sarría y Eduardo Landeta, director y redactor, respectivamente, de la excelente revista de cultura Hermes (Bilbao, 1917-1922), financiada por la familia capitalista de Ramón de la Sota Llano, cuyos hijos colaboraron en ella. Hermes representó un proyecto modernizador, comparable a las empresas culturales del filósofo José Ortega y Gasset (que la presentó en Madrid), por su carácter urbano, cosmopolita y muy pluralista, como prueba que escribiesen en sus páginas destacados intelectuales de las generaciones de 1898 y 1914, muy opuestos al nacionalismo vasco, como Miguel de Unamuno, Pío Baroja y Ramiro de Maeztu.

Hasta su desaparición por el suicidio de su director en julio de 1922, Hermes sirvió de medio de expresión del pensamiento heterodoxo de Sarría y Landeta, quienes propugnaron un nacionalismo liberal y democrático y la «autonomía integral» (como el programa de las Irmandades da Fala en 1918) de Euskadi en España y rechazaron el antiespañolismo (seña de identidad de los aranistas moderados y radicales) por no ver antagonismo ni incompatibilidad entre Euskadi (autónoma) y España (federal): «Euzkadi dentro de España, sí. Pero con su personalidad propia plenamente reconocida, con su libertad respetada» (Hermes, mayo de 2017).

En varios folletos y libros, sobre todo en su Ideología del nacionalismo vasco (1918), Sarría defendió una concepción voluntarista de nación, alejada de la esencialista de Arana, cuyas esencias eran la religión católica y la raza vasca: «La nacionalidad no es sólo la raza, instituciones, lengua y territorio, sino que es también voluntad, deseo de vivir unidos, conciencia y espíritu de comunidad para una acción común», escribió Jesús Sarría. Este abogado aspiró a una España grande, en sintonía con el proyecto de Cambó, y a formar un «gran Estado ibérico», incluyendo a Portugal, en el cual Euskadi tuviese un Gobierno propio. 
Consideraba que el nacionalismo vasco debía renovarse con las ideas de autonomía, democracia, libertad religiosa y reforma social y dotarse de un programa social que integrase a la clase trabajadora, comprendidos los inmigrantes, que no podían pertenecer al PNV por no ser de raza vasca, al no tener apellidos euskaldunes, según la doctrina aranista. Pese a ello, su devoción por Sabino Arana le llevó a dedicarle un número entero de su revista con tan marcado acento hagiográfico que contribuyó al culto sabiniano (Hermes, noviembre de 1919).

Eduardo Landeta, pariente y secretario de De la Sota, fue mucho más lejos en sus planteamientos revisionistas (le he denominado «el Bernstein del aranismo») que Sarría, tanto en sus artículos en Hermes sobre "El problema bizkaitarra» (1917-1920) como, sobre todo, en su importante conferencia titulada Los errores del nacionalismo vasco y sus remedios, publicada en Bilbao en 1923. En ella criticó los dogmas del fundador del PNV y abogó por una triple renuncia: al aranismo, por haberse quedado obsoleto, proponiendo enterrarlo ideológicamente - «iHasta cuándo los nacionalistas vascos [...] van a conservar insepulto el cadáver y las prácticas de Sabino Arana y Goiri?»-; a la restauración foral, por ser una falsedad histórica que el País Vasco fuese independiente hasta la ley de 25 de octubre de 1839, y al independentismo, por considerarlo innecesario. Según Landeta, la meta del nacionalismo debía ser la autonomía de Euskadi dentro de España y, en este sentido, incluso esbozó un proyecto de Estatuto con amplias facultades autonómicas.

Las ideas revisionistas de Sarría y Landeta fueron rechazadas por la Comunión y se hallaban en las antípodas de Aberri. Estos autores heterodoxos no llegaron a crear una tendencia política, pues carecieron de seguidores, pero fueron precursores de Acción Nacionalista Vasca, la primera izquierda abertzale, cuyo manifiesto fundacional (el manifiesto de San Andrés, de 30 de noviembre de 1930) recogió algunas de sus ideas, aunque sin citarles: así, la idea de que el nacionalismo vasco no tenía que ser sinónimo de aranismo, sino que bastaba con la adhesión a la nacionalidad vasca. 


\section{EPÍLOGO}

Como ha quedado patente, la coyuntura de 1916-1923 fue muy importante en la historia del movimiento nacionalista vasco, que vivió dos fases bien distintas: una ascendente con triunfos electorales, sobre todo en Vizcaya, como nunca había tenido antes, hasta 1919, y otra de fracasos, crisis y división en dos partidos entre 1920 y 1923. En ella se frustró el primer intento de autonomía para Euskadi, que fue impulsado por el nacionalismo vasco, contando con el apoyo de otras fuerzas políticas, y constituyó un precedente del proceso autonómico en la II República.

A diferencia del catalanismo y del galleguismo, más plurales ideológicamente, en la Restauración casi todo el nacionalismo vasco continuó siendo aranista, por su fidelidad al fundador, convertido en un símbolo esencial, si bien con dos interpretaciones divergentes de la acción política que habría que desarrollar: la moderada y pragmática, que aceptaba la vía autonómica, y la radical e intransigente, que solo quería la independencia de Euskadi. La doble religión católica y aranista, que caracterizó al movimiento abertzale, hizo imposible la existencia de un nacionalismo vasco de izquierda, cuyos tímidos intentos fracasaron enseguida en las primeras décadas del siglo XX.

Tras el final de la dictadura de Primo de Rivera, que apenas tuvo oposición en Euskadi, en 1930 se produjo la reunificación de comunionistas y aberrianos en el PNV, basada en la ratificación de la doctrina de Sabino Arana (su lema «Dios y Ley Vieja»), y el nacimiento de la izquierda nacionalista con ANV. Esta fue siempre minoritaria en la República, etapa de esplendor del PNV, que llegó a ser el principal partido de Euskadi, si bien tuvo también dos fases muy diferentes: a sus grandes éxitos del bienio 1931-1933, que culminaron con su mayor victoria en unas elecciones a las Cortes en toda su historia (doce diputados), siguieron la crisis interna de 1934-1935 y el retroceso electoral en 1936 (nueve diputados). La lucha entre sus dos tendencias llevó en 1934 a otra escisión de los radicales, encabezados de nuevo por Elías Gallastegui y reunidos en torno al 
semanario bilbaíno Jagi-Jagi (1932-1936), órgano de la Federación de Montañeros de Vizcaya, aunque fue mucho menos relevante que la de Aberri, pues no formaron un partido, sino solo un grupo reducido: Euzkadi Mendigoizale Batza.

A lo largo de la República la nueva generación de jóvenes nacionalistas vascos, liderada por José Antonio Aguirre y Manuel Irujo, logró postergar a la vieja guardia de Luis Arana y, sin atreverse a cuestionar a fondo el aranismo, condujo al PNV del integrismo católico hacia la democracia cristiana, democratizando su organización, para conseguir finalmente el que había sido su objetivo político prioritario desde 1931: el Estatuto vasco, que se aprobó in extremis en la Guerra Civil gracias a la alianza entre Aguirre y Prieto, quienes fueron los padres fundadores de la Euskadi autónoma de 1936-1937. Mas esto se sitúa ya fuera de la etapa histórica aquí analizada. 


\section{REFERENCIAS BIBLIOGRÁFICAS}

Aizpuru, Mikel (2000): El Partido Nacionalista Vasco en Guipuizcoa (1893-1923): orígenes, organización y actuación política, Bilbao, Universidad del País Vasco.

AntXustegi, Esteban (1998): Luis de Eleizalde, un vasco polifacético, Bilbao, Fundación Sabino Arana.

ANTXUSTEGI, Esteban (2007): El debate nacionalista: Sabino Arana y sus herederos, Murcia, Universidad de Murcia.

Arana, Sabino de ([$\left.{ }^{1} 1965\right]$ 1980): Obras completas, 3 tomos, Donostia-San Sebastián, Sendoa.

ArANZADI, Engracio de, Kizkitza (2015): La nación vasca, edición de Luis Castells, Bilbao, Universidad del País Vasco (1. a edición: 1918; reedición: 1931).

BERAMENDI, Justo (2007): De provincia a nación: historia do galeguismo político, Vigo, Xerais.

CASTELLS, Luis (1997): «El nacionalismo vasco (1890-1923): ¿una ideología modernizadora?», Ayer, 28, $127-162$.

CORCUera, Javier ([11979] 2001): La patria de los vascos: orígenes, ideología y organización del nacionalismo vasco (1876-1903), Madrid, Taurus.

ELEIZALDE, Luis de ([11914] 1999): Países y razas: las aspiraciones nacionalistas en diversos pueblos (1913-1914), edición de Esteban Antxustegi, Bilbao, Universidad del País Vasco.

ElorZA, Antonio (1978): Ideologías del nacionalismo vasco, 1876-1937, San Sebastián, Haranburu.

Estévez, Xosé (1991): De la Triple Alianza al Pacto de San Sebastián (1923-1930): antecedentes del Galeuz$c a$, San Sebastián, Universidad de Deusto.

ESTORNÉs, Idoia (1990): La construcción de una nacionalidad vasca: el autonomismo de Eusko-Ikaskuntza (1918-1931), San Sebastián, Eusko Ikaskuntza.

FusI, Juan Pablo (1984): El País Vasco: pluralismo y nacionalidad, Madrid, Alianza.

GranjA, José Luis de la (1998): "O nacionalismo vasco heterodoxo no século XX», Grial, 138, 295-311.

Granja, José Luis de la ([11995] 2002): El nacionalismo vasco: un siglo de historia, Madrid, Tecnos.

Granja, José Luis de la (2003): El siglo de Euskadi: el nacionalismo vasco en la España del siglo XX, Madrid, Tecnos.

Granja, José Luis de la (2015): Angel o demonio: Sabino Arana. El patriarca del nacionalismo vasco, Madrid, Tecnos.

GUDARI (Elías Gallastegui) (1933): Por la libertad vasca: en plena lucha, Bilbao, Verdes.

JUARISTI, Jon (1997): El bucle melancólico: historias de nacionalistas vascos, Madrid, Espasa (varias reediciones).

LANDETA, Eduardo de (1923): Los errores del nacionalismo vasco y sus remedios, Bilbao (reedición: 1931).

LARronde, Jean-Claude (2010): Luis Arana Goiri (1862-1951): historia del nacionalismo vasco, Bilbao, Sabino Arana Fundazioa.

MAINER, José-Carlos (1974): Regionalismo, burguesía y cultura: los casos de Revista de Aragón (1900-1905) $y$ Hermes (1917-1922), Barcelona, A. Redondo (reedición: 1982).

MEES, Ludger (1992): Nacionalismo vasco, movimiento obrero y cuestión social (1903-1923), Bilbao, Fundación Sabino Arana.

NúŃEZ SeIXAS, Xosé M. (2017): «Ecos de Pascua, mitos rebeldes: el nacionalismo vasco e Irlanda (1890-1939)», Historia Contemporánea, 55, 447-482. 
Otaegui, Margarita (1985): «La Triple Alianza de 1923», en Manuel González Portilla / Jordi Maluquer de Motes / Borja de Riquer (eds.), Industrialización y nacionalismo: análisis comparativos, Bellaterra, Universitat Autònoma de Barcelona, 431-441.

PABLO, Santiago de (2015): La patria soñada: historia del nacionalismo vasco desde su origen hasta la actualidad, Madrid, Biblioteca Nueva.

Pablo, Santiago de / José Luis de la Granja / Ludger MeEs (eds.) (1998): Documentos para la historia del nacionalismo vasco: de los Fueros a nuestros días, Barcelona, Ariel.

Pablo, Santiago de / Ludger Mees / José Antonio Rodríguez Ranz (1999): El péndulo patriótico: historia del Partido Nacionalista Vasco. I: 1895-1936, Barcelona, Crítica.

Rodríguez Urriz, M. a Begoña (1993): Una empresa cultural bilbaina: "Hermes, Revista del País Vasco», Bilbao, Diputación Foral de Bizkaia.

RuIZ, Nicolás (2012): Historia de las organizaciones juveniles del nacionalismo vasco (1893-1923), Bilbao, Universidad del País Vasco.

SAllés, Anna / Enric UCELAY-Da CAL (1985): «L'analogia falsa: El nacionalisme basc davant de la Republica Catalana i la Generalitat provisional, abril-juliol del 1931», en Manuel González Portilla / Jordi Maluquer de Motes / Borja de Riquer (eds.), Industrialización y nacionalismo: análisis comparativos, Bellaterra, Universitat Autònoma de Barcelona, 443-470.

SARRÍA, Jesús de (1918): Ideología del nacionalismo vasco, Bilbao, Verdes.

Torres VillanueVa, Eugenio (1998): Ramón de la Sota, 1857-1936: un empresario vasco, Madrid, LID.

UCELAY-Da CAL, Enric (2006): «Entre el ejemplo italiano y el irlandés: la escisión generalizada de los nacionalismos hispanos, 1919-1922», Ayer, 63, 75-118.

UGALDE, Alexander (1996): La acción exterior del nacionalismo vasco (1890-1939): historia, pensamiento y relaciones internacionales, Bilbao, Instituto Vasco de Administración Pública.

UGALDE, Mercedes (1993): Mujeres y nacionalismo vasco: génesis y desarrollo de Emakume Abertzale Batza (1906-1936), Bilbao, Universidad del País Vasco / Emakunde.

UGARTE, Javier (coord.) (2006): «El nacionalismo vasco: mitos, conmemoraciones y lugares de la memoria», Historia y Politica, 15, 5-215.

VV. AA. (1984): Estudios de Historia Social, 28-29: Los nacionalismos en la España de la Restauración.

VV. AA. (1999): Koldo Eleizalde, Donostia, Eusko Ikaskuntza.

VV. AA. (2000): Bidebarrieta, VII: «Hermes» y Bilbao = «Hermes» eta Bilbo, 19-238.

VV. AA. (2017): Repensar Galicia: as Irmandades da Fala, A Coruña, Xunta de Galicia / Museo do Pobo Galego.

YANKE, Germán (2012): Jesús de Sarría, el nacionalista heterodoxo, Bilbao, Muelle de Uribitarte. 